\title{
Coulisses
}

Revue de théâtre

25 | Hiver 2002

Varia

\section{Modalités de l'agit-prop dans le théâtre d'Oswald de Andrade. Étude d'un " procès d'agitation » original}

Héliane Kohler

\section{CpenEdition}

Journals

Édition électronique

URL : http://journals.openedition.org/coulisses/6001

DOI : 10.4000/coulisses.6001

ISSN : 2546-9460

Éditeur

Presses universitaires de Franche-Comté

Édition imprimée

Date de publication : 1 janvier 2002

Pagination : 64-88

ISBN : 2-84627-052-X

ISSN : $1150-594 X$

Référence électronique

Héliane Kohler, « Modalités de l'agit-prop dans le théâtre d'Oswald de Andrade. Étude d'un « procès d'agitation » original », Coulisses [En ligne], 25 | Hiver 2002, mis en ligne le 24 octobre 2019, consulté le 15 novembre 2019. URL : http://journals.openedition.org/coulisses/6001 ; DOI : 10.4000/coulisses. 6001

Ce document a été généré automatiquement le 15 novembre 2019.

Coulisses 
Modalités de l'agit-prop dans le théâtre d'Oswald de Andrade. Étude d'un " procès d'agitation » original

Héliane Kohler

Présentation 
1 Poursuivant la série d'articles consacrée au théâtre brésilien, notamment à la dramaturgie d'Oswald de Andrade (1890-1954), entamée dans le numéro 23 de Coulisses $^{1}$, nous nous proposons d'examiner ici les particularités du discours d'agit-prop présent dans la pièce o homem e ocavalo (L'Homme et le Cheval), et, plus particulièrement, un tableau qui « met en scène » un " procès d'agitation ». Publié, à compte d'auteur, en 1934, interdit par la censure politique, ce texte théâtral n'a été représenté pour la première fois qu'en 1990. Il convient de rappeler que du point de vue politique, les

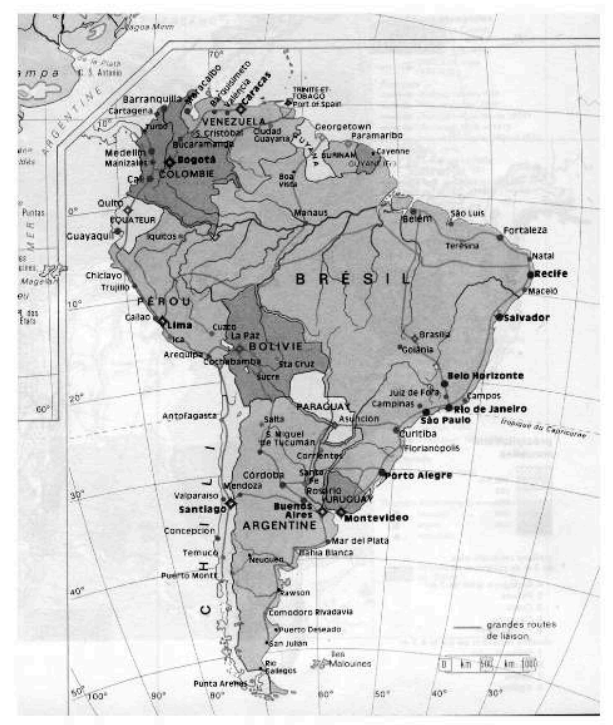
années trente au Brésil correspondent au régime autoritaire et fascisant instauré par le président Getúlio Vargas, au pouvoir, de 1930 à 1945.

Chef de file du mouvement moderniste des années vingt et auteur du célèbre Manifeste anthropophage (1928), Oswald de Andrade ne s'adonne véritablement à l'écriture théâtrale qu'après son adhésion, en 1931, au P.C.B. Dans sa pièce O homem e o cavalo, pour faire passer son message politique, il se sert d'une manière originale des procédés spécifiques mis en œuvre par le théâtre d'agitation et de propagande. Type particulier de pratique théâtrale politique, l'agit-prop, souvent élaborée collectivement, correspond aux manifestations du théâtre militant, révolutionnaire et prolétarien créé en URSS, à la suite de la Révolution d'octobre, et en vogue dans certains pays européens, notamment en Allemagne, jusqu'au début des années trente ${ }^{2}$. En 1932, le "réalisme socialiste », renouant avec les théories esthétiques traditionnelles, met un terme aux activités agit-propistes soviétiques. En 1933, Hitler devient chancelier et les troupes d'agit-prop et du théâtre ouvrier disparaissent définitivement en Allemagne. En dehors de l'Europe, l'agit-prop a eu des répercussions importantes aux USA (en donnant une impulsion notoire au théâtre de gauche); en Amérique latine, ce type de théâtre militant a inspiré quelques dramaturges avant-gardistes communistes. Il convient d'insister sur le lien permanent, instauré par l'agit-prop, entre la visée révolutionnaire et les expérimentations artistiques ${ }^{3}$. À cet égard, il est important de préciser que la théorie du « montage des attractions » (devenue la référence de base du montage au théâtre), conçue par S. M. Eisenstein en 1923, ne se justifie qu'en fonction même de la mise en scène de pièces d'agitation. Eisenstein comprend par " attraction ", « tout moment agressif du théâtre, c'est-à-dire tout élément de celui-ci soumettant le spectateur à une action sensorielle ou psychologique vérifiée au moyen de l'expérience et calculée mathématiquement pour produire chez le spectateur certains chocs émotionnels qui, à leur tour, une fois réunis conditionnent seuls la possibilité de percevoir l'aspect idéologique du spectacle montré, sa conclusion idéologique finale. ${ }^{4}$ Puisque la tâche de tout théâtre utilitaire est de façonner le public-spectateur dans un but idéologique précis, l'outil de façonnage, autrement dit, les différents éléments constitutifs de l'appareil théâtral, doit fonctionner en tant qu'attraction "montée", c'est-à-dire superposée à l'action principale pour mieux agir sur le spectateur. Cette nouvelle méthode de construction 
du spectacle a pour but premier l'efficacité d'un théatre au service de la révolution qui se doit de transformer la conception du monde du public-spectateur.

3 Lors de l'élaboration des sketches d'agit-prop allemands, E. Piscator ${ }^{5}$ se sert $d u$ «montage des attractions» (acrobaties, chansons satiriques, projections, matches de boxe) et du montage de documents (extraits de journaux, de tracts, de rapports, de citations, de films, de photos...). Au niveau verbal et au niveau non verbal, les techniques du montage (textuel/scénique) sont exploitées massivement par l'agitprop: insertion de différents types de discours sociaux (discours politique, discours journalistique, mots d'ordre, slogans, chansons...), de formes d'expression diverses (chants, musique, acrobatie, pantomime), confrontation idéologique (parallélisme bourgeois / révolutionnaire). En effet, l'un des traits spécifiques des pièces d'agitprop concerne leur structuration dialectique et au niveau discursif et au niveau contextuel.

Le montage renvoie en fait à la forme épique. C'est Piscator, avant Brecht, qui, le premier, pose les fondements d'un théâtre épique refusant l'art dramatique traditionnel, aristotélicien (basé sur la progression régulière de l'action, de la tension dramatique, des conflits entre les personnages), le «style» expressionniste (reflétant l'individualisme de l'artiste) et le naturalisme. Le théâtre d'agit-prop suit la tendance d'« épisation", c'est-à-dire, de dédramatisation en tant que théâtre politique/ documentaire où chaque "invention" textuelle/scénique est utilisée en vue de montrer / dénoncer / enseigner / informer / argumenter; bref, de politiser le spectateur, tout en provoquant un impact sur lui. Aussi les éléments épiques (insertion de récits, de commentaires, de chœurs, d'écriteaux, etc.) " mis en scène » par le biais d'un montage (textuel et scénique) sont-ils indissociables de la pratique théâtrale de l'agit-prop. En vue de favoriser la prise de conscience du spectateur, ou plus exactement, de stimuler sa réflexion, afin d'attiser sa réaction, la pièce d'agit-prop se doit de provoquer des effets de choc (coupure/contraste) et, ce faisant, de se servir du montage pour justement créer, à travers la fragmentation et l'hétérogénéité discursives, le dynamisme verbal/visuel tant recherché.

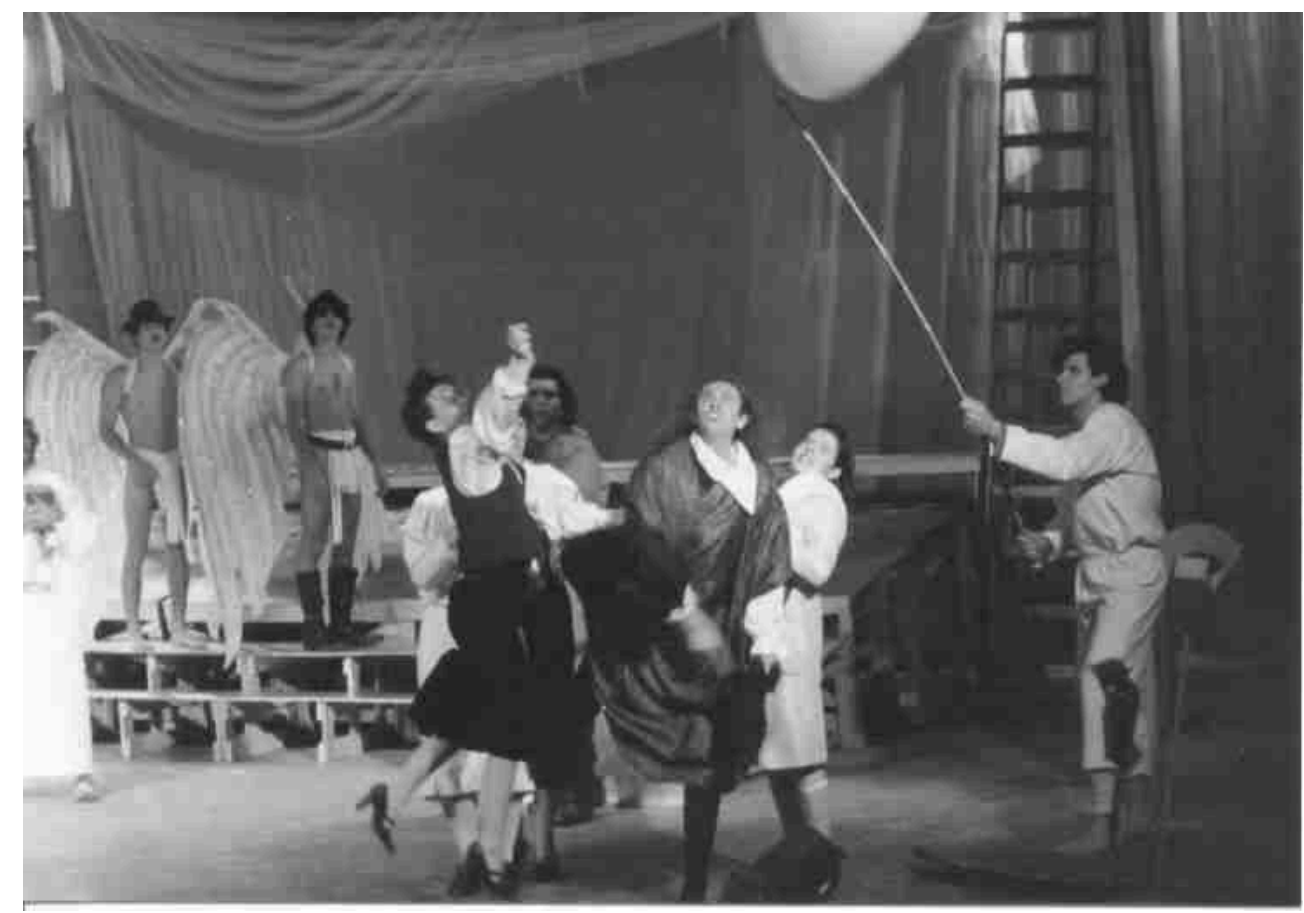

Cliché du Théâtre Universitaire de São Paulo 
Aussi bien en URSS qu'en Allemagne, cette expérience théâtrale pose constamment le problème de la théâtralisation de l'information: les éléments scéniques se doivent de clarifier et de renforcer la portée argumentative du discours d'agitation et de propagande. Dans son souci d'efficacité, ce théâtre devenu un instrument de communication politique réadapte, retravaille et emprunte des formes scéniques traditionnelles (le guignol, le mélodrame, le vaudeville, l'opérette), populaires (cirque, foire, variétés) ou avant-gardistes, et ce, pour mieux agir sur le spectateur. Il convient de préciser que de nombreux dramaturges et hommes de théâtre d'avant-garde, comme Meyerhold, Eisenstein, Arvatov, Tretiakov, Brik, Maïakovski, ont aussi travaillé et écrit pour l'agitprop en URSS. Parmi les formes théâtrales spécifiques utilisées en URSS par le théâtre d'agitation, on peut citer les "agitki» (pièces d'agitation proprement dites), les « agitsud » (les " procès d'agitation »), les « journaux vivants », les pièces dialectiques, les pièces allégoriques, les "scénisations", les montages littéraires ${ }^{6}$. En exploitant un thème précis du répertoire et en se servant des éléments d'agitation (slogans, affiches, pancartes, explications-aphorismes...), l'« agitki » souvent composé en vers rimés ou en prose rythmée faisait référence à la tradition populaire du théâtre de foire. En revanche, l'« agitsud » ou " procès d'agitation ", très utilisé durant la guerre civile par l'Armée rouge et pratiqué, par la suite, surtout à la campagne, visait à représenter le déroulement d'un procès dont l'objet concernait un problème ou un fait tiré de la vie quotidienne (au niveau local ou national), afin de permettre un débat pertinent devant la justice. Comprenant un accusé, qui incarnait le phénomène jugé, ses défenseurs, un accusateur public, le président du tribunal, des témoins, éventuellement des jurés, le procès avait pour but d'expliciter de façon persuasive la position communiste. Favorisant l'élargissement du réseau dialogal, ce type d'agitation constituait un moyen astucieux de faire intervenir le public-spectateur au cours des débats (en tant que jurés, par exemple), et d'entraîner les acteurs-participants à l'argumentation politique et à la répartie. Montés par des cercles de théâtre auto-actifs, les représentations de ce type d'agitation ne comportaient pas de décors et les objets scéniques se limitaient aux tables, aux chaises et aux bancs.

\section{L'agit-prop dans 0 homem e o cavalo}

6 Structurée en neuf tableaux ${ }^{7}, 0$ homem e o cavalo n'est pas une macro pièce d'agit-prop, mais un texte/spectacle politique constitué de nombreux passages relevant de ce type de théatre. En tant que principe structural de la pièce, le thème de la lutte des classes (et corollairement celui de la dénonciation du contexte capitaliste et de la dérision de la bourgeoisie) sur lequel repose l'action dramatique se trouve disséminé tout au long du texte en question, pouvant être facilement repérable dans son parcours discursif et dans celui des acteurs/personnages, regroupés en deux catégories distinctes: les bourgeois (représentant l'ordre établi) et le peuple (les masses-victimes et les révolutionnaires). L'apparition des personnages provenant du deuxième groupe n'a lieu qu'au $4^{e}$ tableau, avec l'« entrée en scène » du premier personnage-ouvrier, révolté et révolutionnaire, le Maître du bateau de Saint Pierre (le contremaître, responsable de la machinerie). Les tableaux précédents présentent les personnages conservateurs venus du « ciel » et le discours du Poète-Soldat (fasciste, raciste, militariste) en faveur de la guerre, adressé aux foules rassemblées dans un stade hippique, en Angleterre. Parmi les nombreux figurants mythiques et historiques (anthropomorphes et non 
anthropomorphes: les chevaux), la plupart ne sont évoqués que verbalement par les seuls acteurs/personnages présents "sur scène " du début au dénouement du texte/ spectacle, à savoir, Saint Pierre et le professeur Icare. Illustrant le grand rassemblement réactionnaire, le $3^{\mathrm{e}}$ tableau représente des scènes d'agitation et de propagande belliciste et fasciste animées par des voix off (procédé scénique largement exploité par l'agit-prop) du Poète-Soldat, de Job et de la Diva (personnage masculin); et des cris / clameurs / vacarme / acclamations indiqués dans les textes didascaliques. Extrêmement nombreux et diversifiés, les représentants de la classe dominante et de la civilisation judéo-chrétienne parodiés et/ou caricaturés appartiennent à différentes catégories de personnages : bibliques (Saint Pierre, Job, le Christ, Madeleine, le baron Barabbas de Rothschild), historiques (Cléopâtre, d'Artagnan, «Mister » Byron); des figurants et personnages types (un petit-bourgeois, un poète catholique), à l'instar des pièces d'agit-prop; des personnages fictifs (Mme Jésus, Mme Icare). D'une manière générale, ces personnages sont identifiés par des noms propres, contrairement aux représentants du camp opposé. Personnages secondaires, les propagandistes révolutionnaires représentant les Soviétiques s'expriment médiatiquement (voix de Staline, voix d'Eisenstein), ou anonymement (le médecin, les trois enfants). Les figurants-agitateurs, à l'exception du Soldat Rouge de John Reed ${ }^{8}$ et du Maître du bateau (devenu, au $8^{\mathrm{e}}$ tableau, le président du Tribunal rouge le Tigre de la mer Noire), s'activent impersonnellement (voix provenant du quai représentant le peuple).

7 La disparition du héros au profit des groupes opposés de personnages étant l'un des traits spécifiques de l'agit-prop, et la notion d'individualité, incompatible avec l'idéal révolutionnaire de ce type de théâtre, il est compréhensible que le discours des figurants et des personnages révolutionnaires soit, somme toute, uniforme et dépersonnalisé, puisqu'il est idéologiquement codé. Agents collectifs d'énonciation, les révolutionnaires prennent la parole en tant que tribuns et organisateurs des masses (le logos étant indissociable de la praxis la parole est un acte politique), et ce, dans le but de persuader les masses, tout en restant à l'écart des intrigues bourgeoises, à l'exception du $8^{e}$ tableau (intitulé «Le Tribunal»), où les personnages révolutionnaires le Soldat Rouge et le Tigre jouent le rôle d'accusateurs, à l'instar des "procès d'agitation» soviétiques, les «agitsud». Cela dit, il n'y a pratiquement pas d'interactions verbales entre les deux groupes opposés. Les allocutions relevant de la propagande et de l'agitation révolutionnaires visent en général d'autres interlocuteurs, à savoir, les ouvriers et la masse représentée scéniquement, ce qui définit la situation du discours et le contexte discursif: l'acte de discours se produit, à l'exception du discours propagandiste dialogal et du "procès d'agitation", sous la forme d'un discours politique de type oratoire. Or, contrairement à la pièce $A M o r t a^{9}$ qui privilégie les joutes dialectiques, c'est-à-dire la «disputatio», la lutte des classes dans Ohomem e cavalo ne se manifeste que rarement sous la forme d'une dispute conversationnelle.

8 Aussi l'espace scénico-textuel occupé par les révolutionnaires est-il quantitativement inférieur à celui occupé par les représentants de l'idéologie dominante. En d'autres termes, les locuteurs conservateurs multiples et hétérogènes, burlesques et grotesques monopolisent l'aire du jeu et le discours théâtral. Luttant pour une même cause, jouant sur le registre du réel, introduisant le monde extérieur, à savoir, l'Histoire dans l'ordre du fictionnel, le petit groupe (homogène et solidaire) des militants, fait irruption dans le contexte bourgeois, et cette incursion, tout en ayant comme prétexte l'agitation 
politique, fait émerger un discours pragmatique, et, par là même produit un effet de réel.

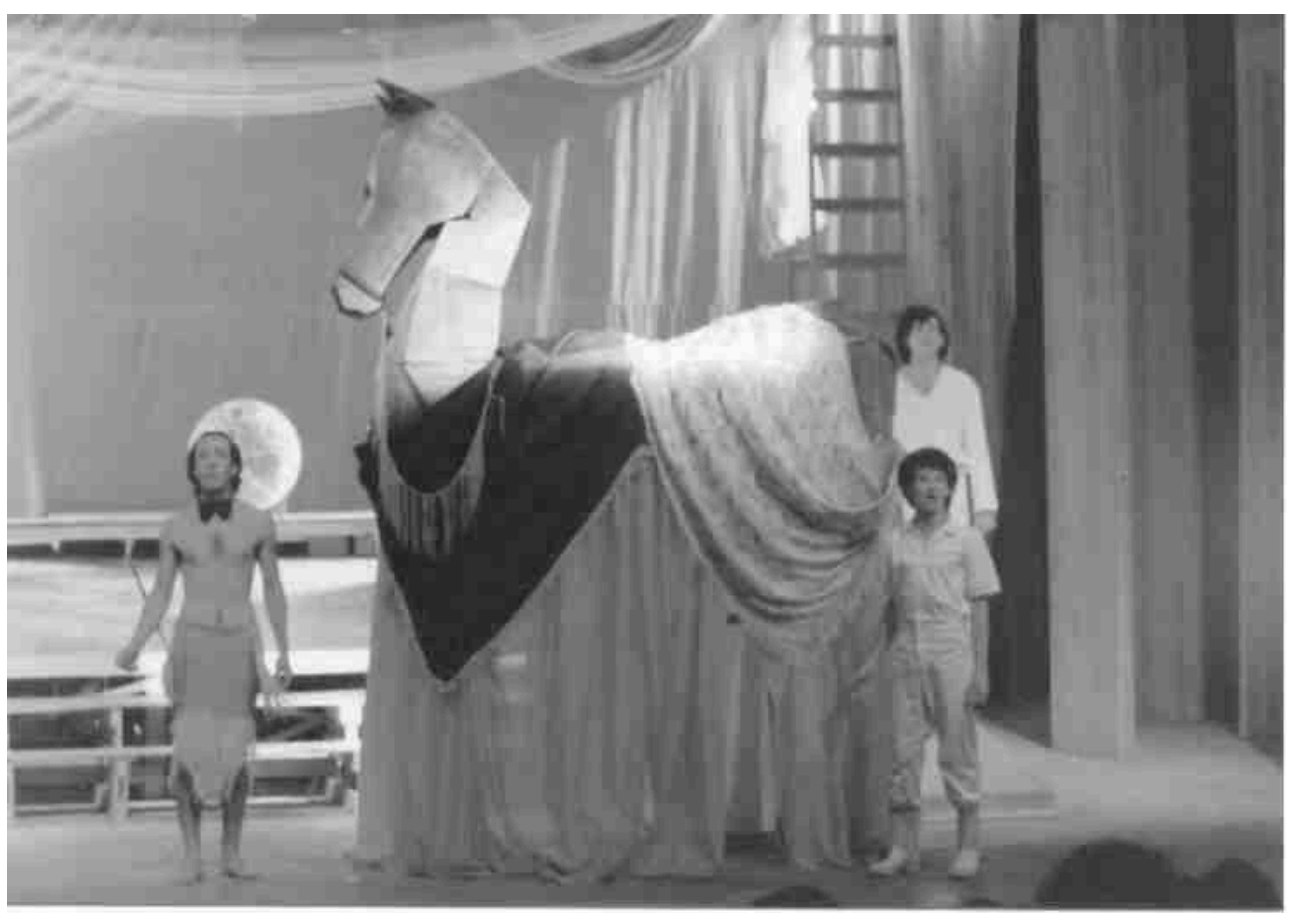

Cliché du Théâtre Universitaire de São Paulo

\section{« Le Tribunal » - un « procès d'agitation »}

Le "procès d'agitation» («agitsud»), on l'a dit précédemment, fut l'une des formes spécifiques utilisées en URSS par le théâtre d'agitation. «Son but était de permettre un débat judicieux qui dégageât de façon persuasive la position communiste sur un phénomène quelconque de la vie et de l'enseigner aux masses, à travers des personnages vivants. $»^{10}$ Les sujets propres à un "procès" étaient nombreux: problèmes agronomiques (à la campagne), relatifs à l'éducation politique, aux mœurs, à l'hygiène, etc. Une fois le sujet fixé, un débat était préparé suivant le schéma d'un véritable procès de justice. Il est important de préciser que «le phénomène jugé était incarné par l'Accusé qui, par son type extérieur, son comportement, sa situation sociale, son niveau d'instruction, devait être représentatif de ceux qui en étaient partisans, qu'il fût bon ou mauvais. $»^{11}$ Le président du tribunal révolutionnaire déclarait la séance ouverte et donnait l'ordre de faire entrer l'accusé qui se plaçait, ensuite, en face de lui et de l'accusateur public ${ }^{12}$. Aux côtés de l'accusé, il y avait ses défenseurs. En fonction du cercle qui montait le spectacle, on ajoutait des jurés choisis dans le public. Il fallait également prévoir l'audition des témoins et, éventuellement, d'experts. Une fois l'audience terminée, le tribunal révolutionnaire rendait sa sentence (condamnation ou acquittement). En effet, le verdict exprimait l'«appréciation correcte du phénomène mis en jugement $»^{13}$, en proposant souvent des solutions. Le jugement était évalué selon un point de vue de classe, devant un public qui le suivait avec une attention toute particulière témoignant un intérêt certain pour le déroulement du procès (qui laissait une large place à l'improvisation) et la décision de l'affaire représentée. 
Selon le texte didascalique qui présente le $8^{\mathrm{e}}$ tableau de la pièce d'Oswald de Andrade, intitulé "Le Tribunal », "la scène représente la salle de l'ex-prix Nobel, érigée en tribunal révolutionnaire. Au fond, une grande porte qui s'ouvre sur le paysage classique du Golgotha, avec seulement deux croix. ${ }^{14}$ Faisant référence à deux contextes spatio-temporels distincts $\left(\mathrm{XX}^{\mathrm{e}}\right.$ siècle - " pays socialiste " / $\mathrm{I}^{\mathrm{er}}$ siècle - la Palestine), ce tableau confronte, une fois de plus, le présent (ou "monde socialiste ", avec toutes les connotations qu'il comporte dans la pièce de positif et de dynamique) au passé. Le présent (transformation/ évolution/progrès) se proposant de juger le passé, représenté iconiquement par le "paysage classique du Golgotha» (dans les Évangiles, colline où eut lieu la crucifixion de Jésus). Le présent (la nouvelle société) ayant pour tâche de démolir tout ce qui, relevant du passé, fait obstacle à la construction socialiste. Ainsi les priorités du présent exigent-elles la transformation d'un espace destiné auparavant au prix Nobel (lieu où l'on récompense un savant), en tribunal (lieu où l'on rend la justice) révolutionnaire (les affaires devant être jugées selon un point de vue de classe, à savoir, une optique novatrice), contrairement au tribunal du passé15. Or, un signe de cette nouvelle vision historique est à relever dans le texte didascalique : «le Golgotha avec seulement deux croix » et non pas trois, malgré la précision antérieure : «paysage classique du Golgotha ».

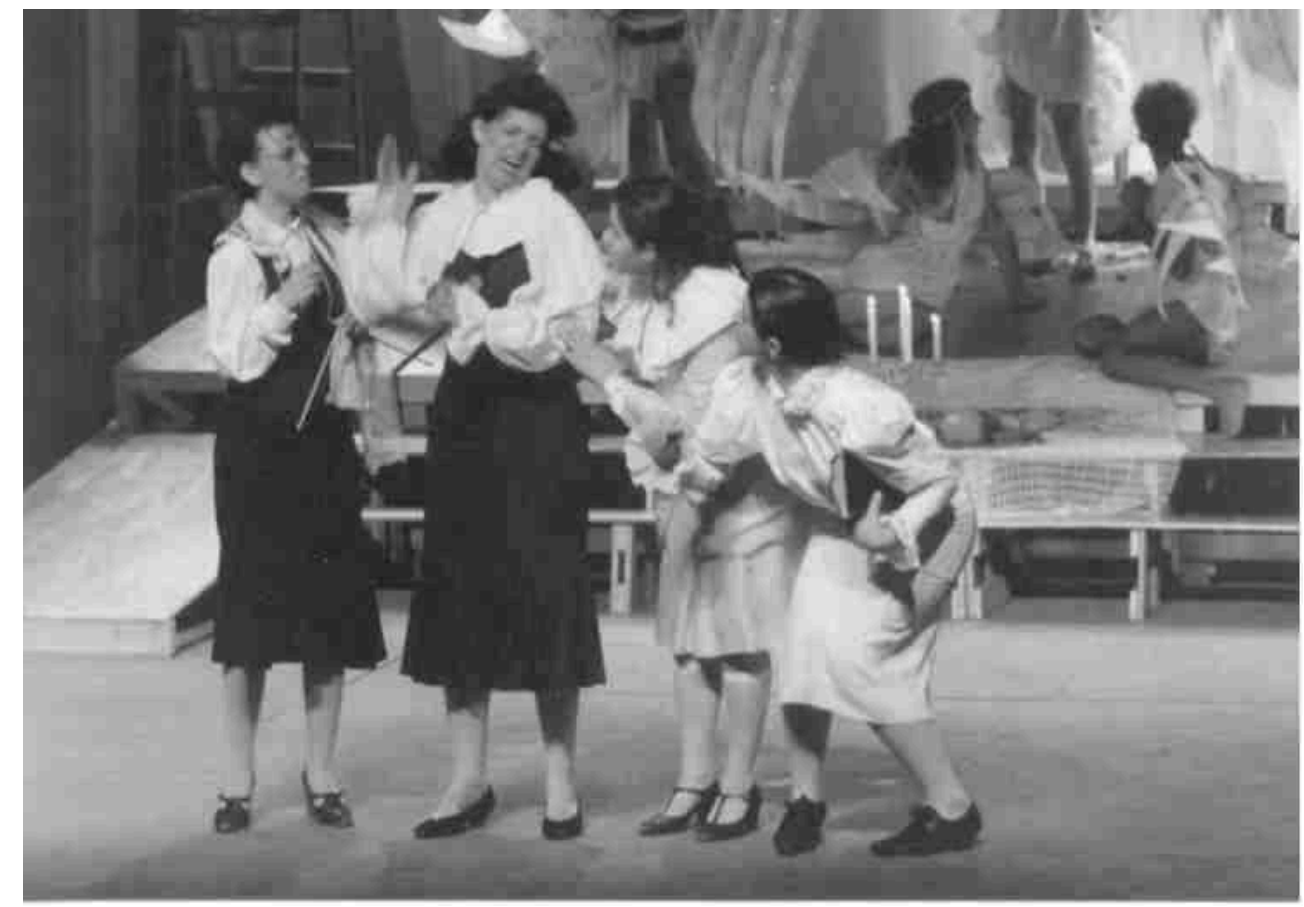

Cliché du Théâtre Universitaire de São Paulo

11 Le plus long tableau de la pièce et le plus inventif, "Le Tribunal» est celui qui comporte le plus grand nombre de personnages (18 au total). Très hétéroclites, les participants se répartissent en deux groupes : les conservateurs et les révolutionnaires. À l'intérieur de ce dernier groupe se trouve le président du tribunal, le Tigre assisté de la camarade Vérité (personnage allégorique) ; le Soldat Rouge (ce personnage agitateur, présent également dans le $5^{\mathrm{e}}$ tableau, est l'accusateur officiel); le personnage intertextuel Véronique (exerçant des fonctions administratives dans l'État soviétique); un romancier anglais (depuis la salle, ce personnage intervient pour renforcer les accusations sur l'inculpé) ; et des « voix » qui appuient les accusateurs. Il faut préciser 
qu'à plusieurs reprises la séance est perturbée par des interventions, provenant de la salle, d'un spectateur fictif, d'un petit bourgeois, d'un poète catholique des personnages types représentants du groupe conservateur. Selon le Soldat Rouge, il y a deux accusés, le Christ et sa dame, Mme Jésus (en français dans le texte). En fait, Mme Jésus (elle n'est accusée que parce qu'elle est l'épouse de l'inculpé) se comporte davantage en tant qu'avocate de son mari, l'accusé principal, ou plus exactement, celui qui incarne les phénomènes jugés. Ainsi, la plaidoirie n'est-elle assurée que par les deux "accusés" méritant l'approbation de quelques "voix» provenant de la salle. Le personnage intertextuel (biblique) Madeleine explique sa présence au tribunal en tant que témoin. Or, non seulement ce personnage n'est pas convoqué à l'audience, mais, dès la rentrée des accusés, il prend place juste derrière le Christ dans une "position de modèle ». Appelé par l'accusé à venir à son aide, Saint Pierre jouera le rôle de témoin/ accusateur. Presque à la fin de la séance, un autre personnage intertextuel demande la parole Barabbas, ou plutôt, le baron Barabbas de Rothschild. Dans les Évangiles, Barabbas était le voleur condamné à mort et gracié à l'occasion de la Pâque, sur la demande de la foule, alors que Pilate proposait de libérer Jésus. D'autres personnages intertextuels comme le bandit chinois Fu Manchu (personnage de bande dessinée) et d'Artagnan (personnage historique et romanesque) font irruption sur la scène interrompant momentanément le déroulement du procès. Par ailleurs, les didascalies signalent la présence d'innombrables figurants: scène 1 ("des soldats romains, des femmes, des apôtres, des esclaves la foule qui avait été chez Pilate.»); scène 3 ("des voix d'eunuques et de vieilles femmes"); scène 4 ("le peuple et les personnages de la salle.") À l'instar des "procès d'agitation» soviétiques ("agitsud»), le peuple (représenté scéniquement dans $O$ homem e ocavalo par le public fictif) suit avec un intérêt certain l'affaire jugée, en intervenant bruyamment durant le jugement.

La disposition actorielle disparate constitue l'un des éléments du montage original produit par Oswald de Andrade dans un but idéologique manifeste: donner un éclairage «brutal $\aleph^{16}$ aux phénomènes politiques. L'espace scénique est un assemblage de lieux disjoints spatialement et temporellement et de personnages hétéroclites, juxtaposés anachroniquement et appartenant à des contextes idéologiques distincts. Ce montage parallèle qui, comme on le verra plus loin, se présente sous d'autres aspects, se manifeste également par la juxtaposition de faits appartenant tantôt au $\mathrm{I}^{\mathrm{er}}$ siècle, tantôt au $\mathrm{XX}^{\mathrm{e}}$ siècle ; faits, qui par leur contraste, visent à afficher les antagonismes de classe. Ainsi que le précise Claudine Amiard-Chevrel, au sujet des montages littéraires dans le théâtre soviétique des années vingt, « l'assemblage organisé d'éléments volontairement hétérogènes dans le domaine du texte et dans le domaine de la mise en scène permet à la fois de reconstituer une fresque historique, de rendre clair le mécanisme d'un épisode d'histoire ou d'un fait politique, de multiplier les niveaux d'explication politique de la façon la plus simple et la plus accessible, chaque élément jouant son rôle par rapport à l'autre exactement comme les données politiques d'une situation se combinent, se cumulent ou s'annulent pour produire la situation, ou conditionner son évolution. $»^{17}$

13 Le but du tribunal dans les " procès d'agitation » soviétiques est, on l'a dit, de juger une affaire selon un point de vue révolutionnaire et d'afficher, pendant le déroulement du procès, la position communiste. Aussi faut-il rappeler que dans le théâtre d'agit-prop le personnage constitue un support du dialogue politique; en l'occurrence, dans les procès d'agitation, le personnage de l'accusé incarne le(s) phénomène(s) jugé(s). Par 
son type extérieur, par son comportement, sa situation sociale, l'accusé doit être représentatif de ceux qui en sont partisans. Figure centrale de la religion chrétienne et chef suprême de l'Église, l'accusé du tribunal révolutionnaire de O homem e o cavalo, le Christ, fait l'objet d'un jugement, d'une part, parce qu'il incarne les croyances religieuses relevant $d u$ "monde ancien», et, d'autre part, parce que, «Dieu de la bourgeoisie " (selon les "voix" anonymes), il incarne la cible à combattre dans le contexte socialiste. En tant qu'«avocate» de son mari, Mme Jésus représente également l'idéologie bourgeoise. Cela dit, il ne s'agit pas d'un procès contre le personnage historique du Christ lui-même, mais contre ce qu'il incarne, et qui fait obstacle à la construction socialiste.

En effet, pour les juges révolutionnaires, ce qui est important, c'est d'« éliminer les deux classes. » (p. 207) Dans ce tableau, Oswald de Andrade allie la parodie à la satire dans la mesure où le discours d'agitation vise une cible extratextuelle (les phénomènes jugés: la religion, l'Église, les mœurs bourgeoises, l'antisémitisme, le nazisme, les profits capitalistes, etc.), mais utilise la parodie (les Évangiles et la tradition chrétienne) en tant que "dispositif structurel pour réaliser son but correctif. $»^{18}$ En tant que véhicule de la satire, la parodie ne vise donc pas à attaquer les Évangiles (texte parodié principal), mais à étayer l'agression satirique.

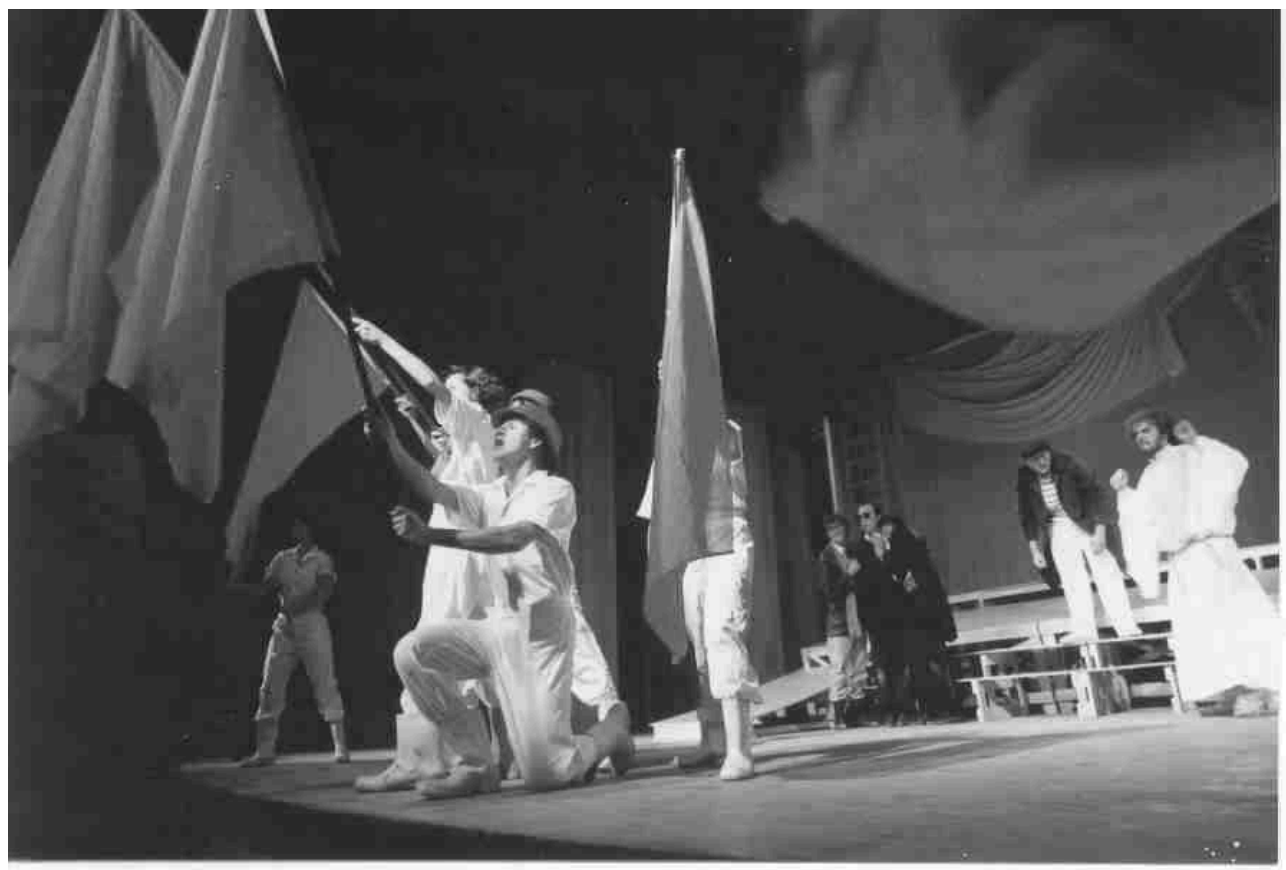

Cliché du Théâtre Universitaire de São Paulo

\section{Une satire parodique}

On ne saurait saisir toute la portée corrosive de ce "procès d'agitation", sans auparavant expliciter quelques traits spécifiques de ce type de discours comique qu'est la satire sociale et politique. "Aux arguments rigoureux que l'intelligence dicte à toute personne, s'ajoute un moyen sûr, indéfectible : le mépris assorti d'une moquerie bien dosée qui rebat l'adversaire et lui fait perdre pied aux yeux d'un observateur averti. La défaite de l'autre n'est pas seulement intellectuelle, sur le plan des idées, mais elle atteint aussi sa dignité. La satire a ceci de particulier qu'elle ravale au rang de victime, 
et ce, au niveau du discours seulement, celui qui, dans la réalité, est très souvent en position de force $"{ }^{19}$ Elle constitue une arme de combat privilégiée contre les formes sociales sclérosées, mais cependant $"$ malfaisantes $»^{20}$ que le satiriste militant utilise pour mieux les démolir. "Ce militantisme de propagation de la foi », selon l'expression de Denise Jardon ${ }^{21}$ est mené au moyen de l'ironie (la satire, comme le dit Northrop Frye, est de l'ironie militante ${ }^{22}$. Or, le satiriste (censé posséder la vérité) combat, par ailleurs, des normes morales généralement admises, en installant un modèle présenté comme « la norme » à suivre.

Northrop Frye explicite la satire par ses exigences d'un minimum de fantaisie et d'un contenu que le lecteur doit trouver grotesque. En d'autres termes, la satire, selon Frye, ne fonctionne plus en tant que telle lorsque son contenu est trop " oppressivement réel pour permettre de maintenir le ton de fantaisie ou de l'hypothèse"; ce qui la caractérise étant finalement « un double foyer de moralité et de fantaisie $»^{23}$. En effet, la satire est investie d'une intention de corriger qui doit être axée sur une évaluation négative de la cible visée; d'où l'usage fait par le discours satirique de l'ironie moqueuse et dépréciative, de la dérision ridiculisante à des fins réformatrices ${ }^{24}$.

Développant une rhétorique du mépris, le discours satirique se caractérise par une distanciation extrême avec l'idéologie opposée. Cela dit, la satire constitue un type de discours agonique, de combat, affichant une coupure radicale avec le monde antagoniste conçu comme "absurdité, chaos et malfaisance ", comme le précise Marc Angenot $^{25}$. Pour caricaturer le point de vue de l'adversaire, jugé absurde, le satiriste utilise un miroir déformant. Il est important, par ailleurs de souligner l'interdépendance de la satire, de l'ironie mais aussi de la parodie. Si la cible visée par la parodie est intertextuelle (un autre texte ou une série de conventions sociales), le but de la satire est social ou moral, et, par conséquent, extratextuel. Quoi qu'il en soit, la satire peut étayer ses attaques en se servant de la parodie, comme c'est le cas dans le « procès d'agitation » de la pièce d'Oswald de Andrade.

Composé de 8 scènes, le tableau en question concerne trois moments significatifs: 1) avant le procès (ou plutôt, avant la « révision du procès du Christ ») rencontre des personnages intertextuels, Saint Pierre, Véronique (dans la légende chrétienne, c'était la sainte femme qui aurait essuyé le visage du Christ lors de la montée au Calvaire) et Madeleine ; 2) l'arrivée carnavalesque au Tribunal Rouge de Mme Jésus et de son mari, le Christ; 3) le jugement de l'accusé correspondant au "procès d'agitation" proprement dit. Dans le cadre de cet article, nous nous limiterons à examiner les éléments les plus marquants de ces trois moments.

Dans la première scène, le personnage intertextuel Véronique, chargé de préparer la carte d'identité des accusés, tient une grande photo sur laquelle, d'après le texte didascalique, on voit "Adolf Hitler crucifié sur une croix gammée.» (p. 203) Reconnaissant la photo, Saint Pierre désigne le Christ, «le Christ roi », ce qui est confirmé par Véronique: «Parfaitement! Le chancelier Christ, la dernière incarnation de l'antisémitisme.» (p. 204) La confrontation texte parodié/texte parodiant permettra d'exhiber leurs divergences sémantiques responsables de la subversion sémiotique de la représentation iconique de l'accusé :

Texte parodié (légende chrétienne) Texte parodiant 


\begin{tabular}{|l|l|}
\hline - linge & - pellicule \\
- visage du Christ & - image de l'accusé \\
- « voile de Véronique » & - photo grand format \\
- empreinte du visage du Christ & - Hitler crucifié sur la croix gammée (photomontage) \\
\hline
\end{tabular}
parodié (objet d'un jeu parodique), mais l'accusé, dans la mesure où il est assimilé à Hitler. En effet, l'agressivité iconoclaste et blasphématoire des premières scènes ne concerne pas le texte parodié, mais les différentes analogies établies à l'intérieur du propre texte parodiant. Aussi l'impact agitationnel (visant à une réaction de la part du spectateur) provoquée par la représentation iconique de l'«accusé » est-il en fait double : d'une part, le personnage de la photo, ou plutôt du photomontage, Hitler, se trouve dans la même posture que le Christ (crucifié), même si la croix gammée remplace la croix, et, d'autre part, l'assertion identificatrice de Saint Pierre ( $C^{\prime}$ 'est le Christ.») est confirmée et explicité par le personnage parodiant Véronique. Or, l'identification de l'accusé en tant que personnage nazi constitue la première grosse charge qui pèse sur lui, et, en l'occurrence, le premier phénomène à combattre par le tribunal révolutionnaire. En effet, l'attaque satirique n'est pas menée contre le personnage parodié, anachronique, mais bien contre l'idéologie que l'accusé est censé représenter.

21 À partir de la scène 3, comportant l'annonce faite par le Soldat Rouge de l'arrivée imminente des accusés, jusqu'à leur entrée au tribunal (scène 5), la carnavalisation investit doublement le texte/spectacle en transformant, d'une part, l'espace " scénique » dans une aire de jeu et de fête ; en entraînant, d'autre part, au niveau du discours, une multiplicité de registres, de niveaux de langue spécifiques à la liberté verbale du carnaval populaire. Nombreux sont les procédés comiques et carnavalesques présents dans ces trois scènes: chant parodique, moquerie, critique sociale, imprécations, jurons, travestissement parodique et grotesque, couple carnavalesque... À l'instar des fêtes traditionnelles populaires, l'«action» est censée se dérouler à l'extérieur de la salle du tribunal, dans un espace ouvert - occupé par des acteurs figurants anonymes. La foule enthousiaste s'exprime librement, des voix s'élèvent pour acclamer l'accusé, d'autres, pour le blâmer. À l'instar du carnaval - spectacle sans la rampe et sans la séparation en acteurs et spectateurs -, les «personnages de la salle » se mélangent au "peuple» pour assister à l'arrivée des accusés. À l'extérieur du tribunal, c'est alors un charivari pareil à celui du carnaval. La « fête » commence par un chant, ou plus exactement, par la parodie d'un cantique religieux entonné par des «voix d'eunuques et de vieilles femmes » accompagnées à l'orgue. La profanation, thème carnavalesque par excellence, est à relever dans le "cantique" parodique à plusieurs niveaux: locuteurs, personnage, référent, intentionnalité. Ce sont des "chanteurs" anachroniques et impuissants qui, avec leurs voix affaiblies et dissonantes chantent en chœur le " cantique » érotique, ou plutôt phallique, où l'accusé est présenté de manière grotesque : sa tunique blanche faisant ressortir son emblème désacralisée : les armes, pistolet, poignard objets phalliques qui, par ailleurs connotent la violence et le gangstérisme. Introduisant le sacrilège carnavalesque, la parodie du cantique fournit ainsi, de façon anticipée, une description sémiotique (signes vestimentaires, accessoires) du personnage dans son rôle thématique de l'accusé. Entre 
le texte parodié (cantique d'église chanté à la gloire de Dieu) et le texte parodiant (" cantique » satirique chanté pour ridiculiser l'accusé) s'installe un décalage ironique de type hyperbolique propre à la transgression parodique/carnavalesque. Aussi, le comique (véhiculant un thème d'agitation antireligieuse) relève-t-il de l'«esprit tendancieux » qui, d'après Freud, «se prête (...) bien à l'attaque contre tout ce qui est grand, respectable et puissant et que l'inhibition intérieure ou les circonstances extérieures préservent de la déconsidération directe. $»^{26}$

Cet «intervalle» carnavalesque, qui se déroule à l'extérieur du tribunal avant le jugement, est constitué d'innombrables «attractions» (éléments scéniques autonomes) : "sons de castagnettes » montage sonore signifiant, annonçant l'arrivée du personnage espagnol, Mme Jésus; association du "spectacle » à une corrida (Mme Jésus, par sa grossièreté comportementale, est assimilée à un taureau : "Viva la gracia! Otro toro!»); entrée " cirquesque » et grotesque des accusés. Il s'agit en effet d'un couple carnavalesque défini par l'excentricité et la mésalliance. Personnage autoritaire aux attitudes viriles, Mme Jésus joue le rôle masculin de "garde du corps " de son mari, personnage consentant et obéissant. Construite selon la méthode désignée par le nom de "grotesque ", l'« image » des deux personnages ne renvoie donc pas à la " norme » sociale, mais elle se présente de façon difforme : la déformation de l'accusé se situe au niveau vestimentaire et celle de l'accusée, au niveau comportemental (gestes et paroles). Décrits dans le cantique parodique, le costume et les accessoires du personnage du Christ sont détaillés lors de son arrivée au Tribunal : «Le Christ apparaît armé d'une panoplie de toutes les époques. Chemise évangélico-fasciste et un havresac. Casque d'épines. Tunique d'un blanc éclatant. Un parapluie noir.» (p. 208) Ce travestissement parodique, réalisé à l'aide d'un " montage corporel » ${ }^{27}$, fait du personnage (dans le rôle de l'accusé), un mélange de bandit / soldat / fasciste / religieux. Si aucune indication concernant l'accoutrement du personnage Mme Jésus n'est formulée dans les textes didascaliques, en revanche, son aspect grotesque et clownesque est souligné par ses attitudes impolies et grossières (elle entre dans la salle du tribunal en poussant son mari), rehaussé par ses propos obscènes (procédé carnavalesque et satirique) exprimés en espagnol macaronique, exhibant son incontinence verbale. On comprend mieux l'assimilation faite par la foule entre Mme Jésus et le taureau; les limites entre anthropomorphe/non anthropomorphe n'étant pas rigides dans le grotesque. En effet, le grotesque situe ce couple carnavalesque à la frontière du tragique (l'accusé sera condamné par le tribunal révolutionnaire) et du risible (Mme Jésus est, on l'a dit, un personnage clownesque). Les raisons de la déformation grotesque des deux personnages sont dues à la satire social et politique qui propose, toujours dans un but critique et railleur, une vision déformée de la réalité et des cibles visées, rabaissées à souhait.

L'interrogatoire commence à la scène 5 et c'est Mme Jésus qui répond la première. Or, la «mise en scène " de ce personnage est fondée sur un montage libre d'attractions basées sur des situations clownesques et bouffonnes au niveau discursif et scénique. En effet, la présence scénique de ce personnage clownesque est orientée vers la satire sociale et religieuse qui brosse un portrait grotesque du couple (carnavalesque) des accusés : Mme Jésus incarne l'élément fort qui doit sans cesse veiller sur le personnage vulnérable, son époux. La "théâtralité " provoquée par le comportement discursif, gestuel, proxémique du personnage est, par ailleurs, renforcée, lorsque Mme Jésus s'adresse au public spectateur (procédé clownesque) et menace les communistes présents dans la salle. Aussi cette attraction scénique vise-t-elle à l'efficacité 
agitationnelle du tableau en question. En effet, tout en visant à provoquer l'hilarité, la présence "scénique" de la femme de l'accusé répond à un but satirique et agitationnel: renforcer, par la moquerie, l'attaque contre les deux personnages "gardiens officiels» de la morale bourgeoise/chrétienne. La "mise en scène » carnavalesque et clownesque de Mme Jésus affiche toute l'irrévérence et subversion voulues par Oswald de Andrade dans ce "procès d'agitation " politique. Par ailleurs, les scènes 5 et 6 , comportant les personnages parodiques Fu Manchu et d'Artagnan, sont conçues à partir d'un montage libre d'attractions, qui, par des jeux excentriques, renvoie également à des numéros de clown. Les attractions libres, inspirées du cirque et insérées à l'intérieur de la séance du tribunal (de la scène 5 jusqu'à la scène 8 , la dernière) se présentent de manière discontinue, c'est-à-dire, elles ne sont pas enchaînées les unes aux autres. Si la "mise en scène » de Mme Jésus est en quelque sorte intégrée à l'«action » centrale, à savoir le procès du Christ, en revanche, les attractions ayant pour « clowns » les personnages Fu Manchu et d'Artagnan constituent des numéros autonomes. Selon Eisenstein, faut-il le rappeler, l'attraction est tout élément autonome de la construction du spectacle ayant pour objectif un certain effet thématique final (la conclusion idéologique du spectacle), tandis que l'agitation constitue toute action contre l'état de choses à combattre; le thème agitationnel du procès étant la lutte contre les croyances religieuses et les valeurs bourgeoises. À l'instar des personnages bourgeois du théâtre d'agit-prop, qui naïvement avouent leurs torts, le personnage Mme Jésus, par sa loquacité importune, ne fait que porter des " coups " à l'accusé et aggraver, de la sorte, les accusations portées sur lui. Sa "maladresse » discursive, spécifique à son rôle clownesque, fait ressortir une grave accusation contre son mari : un petit bourgeois propriétaire de deux bungalows.

MME JÉsus. - Pero la guerra nos molestô tambien. Como no ? Los aeroplanos e los

canones destruiram dos casitas-bengalôs que teniamos! (p. 209)

Reflétant la moquerie irrévérencieuse du dramaturge, le grotesque et la fantaisie (spécifiques à la satire) proviennent non seulement de la transformation / déformation parodique, mais aussi de la carnavalisation des accusés et de la cirquisation de certains personnages dont la " mise en scène » est basée sur des attractions libres constituées de jeux de scènes excentriques, bouffons. Cela dit, l'examen des moments les plus significatifs du «jugement" proprement dit, aura pour objet de mieux révéler les éléments de fantaisie et le grotesque à travers la parodie biblique (il s'agit de la révision du procès du Christ) et d'expliciter les jugements moraux et les attitudes militantes du dramaturge/satiriste. Il convient de rappeler que, pour le satiriste, son opinion est érigée en vérité unique, et de ce fait, le point de vue de l'adversaire ne saurait être considéré que faux et absurde. Or, c'est précisément sur le terrain de l'adversaire que le satiriste mène son combat en utilisant à la place d'un raisonnement suivi, un miroir déformant pour caricaturer l'opinion d'autrui.

La première accusation énoncée par le président du tribunal, le Tigre, à l'accusé, a en effet trait à une réflexion d'ordre métalinguistique; il s'agit de montrer le lien sémantique existant entre le signe verbal «Dieu » et les manifestations patriotiques, d'où le rapport direct Dieu / nationalismes, xénophobies, guerres. C'est parce que le mot « Dieu » est utilisé dans différentes langues à l'intérieur d'expressions chauvines que le Christ est accusé d'être « un élément instigateur de toutes les guerres ».

LE TIGRE. - (...) Vous êtes présent dans tous les hymnes et dans toutes les bêtises nationales. Lorsque les Allemands veulent tuer quelqu'un, ils disent GOT MIT UNS! 
Les Français disent DIEU GARDE LA FRANCE et les Anglais GOD SAVE THE KING !

(p. 209) d'un métadiscours critique qui ne vise nullement à s'en prendre au texte premier, mais à soutenir le discours agonique de la satire. Saint Pierre, accusateur, combat, en l'occurrence, l'adversaire sur son propre terrain, en tant que témoin de ses agissements passés, et ce, pour mieux développer la double stratégie du discours agonique: démonstration de la thèse et réfutation/disqualification de la thèse adverse ${ }^{28}$. Cela dit, toutes les assertions de l'accusé sont réfutées par Saint Pierre qui sournoisement tente de déployer une série d'arguments révolutionnaires qui, tous, convergent vers la conclusion: le Christ est coupable de la réaction dans le monde, des fascismes historiques, de l'oppression à travers les siècles. Or, tout le discours agonique de Saint Pierre, dans son rôle d'accusateur, se construit par dénégation et dérision dans la mesure où il doit s'installer dans un point extrême de divergence idéologique avec l'accusé.

30 «Le surnaturel de la procréation » constitue, par ailleurs, un exemple manifeste d'argument saugrenu défendu par l'accusé qui sera catégoriquement réfuté par le «spectateur » qui intervient de la salle, à savoir, le romancier anglais. Ce faisant, ce personnage, dans le rôle d'un accusateur, développe une contre-argumentation satirique tentant de prouver l'absurdité mensongère du raisonnement adverse. Si le « public » du tribunal partage les courants d'opinions exprimés par les accusateurs, la doxa se fait entendre dans la salle du jugement par les représentants du camp conservateur, tel un petit bourgeois qui s'indigne des propos adressés contre l'inculpé.

31 Ainsi que le précise Matthew Hodgart ${ }^{29}$, « d'une façon générale, la satire tend à ramener tout à l'élémentaire : elle ne cesse d'invoquer le sens commun, la raison et la simple logique. " Cela dit, tout au long du "procès d'agitation ", la distorsion parodique se construit en fonction de la démystification du surnaturel. Alors que dans le texte parodié la disparition du corps de Jésus du tombeau s'explique par sa résurrection, dans la version parodiante, selon le romancier anglais, si le sépulcre était vide, c'est parce que le Messie (qui n'était pas mort) était allé chez le médecin. " Il était normal que les femmes ne retrouvent pas le Messie dans le sépulcre », explicite le romancier anglais. Le discours satirique reproduit en un miroir déformant l'absurdité du monde antagoniste dont le rapport avec la logique universelle est celui de l'inversion, du monde à l'envers. ${ }^{30}$ Lorsque le président du tribunal demande à l'accusé d'élucider le 
passage du texte de Mathieu 5, verset 25 : «Mets-toi vite d'accord avec ton adversaire pour qu'il ne te jette pas en prison. »; il redit les paroles des Évangiles :

LE CHRIST. -J'ai enseigné : si quelqu'un te gifle sur la joue droite, tends-lui la joue gauche.

SAINT PIERRE.-En langage politique, cela veut dire : si le Romain te prend la Judée, offre-lui la Galilée. (p. 215)

N'apportant aucune explicitation à son enseignement biblique (son discours citationnel constituant un simple collage textuel), l'interprétation de la maxime revient aux accusateurs, de surcroît, Saint Pierre, dans son rôle de témoin accusateur « révolutionnaire». Son intervention satirique, affichant son attitude militante et ses jugements moraux, non seulement réfute la parole du Maître, mais démontre le danger d'une telle thèse : sa mise en œuvre équivalant à accepter passivement l'impérialisme romain ce dont le Christ est accusé.

C'est à partir du fragment parodié, « Rendez donc à César ce qui est à César, et à Dieu ce qui est à Dieu ", constituant une pièce à conviction pour l'accusation, que le président du tribunal révolutionnaire table sur la « démonstration » de la culpabilité de l'accusé en tant qu'agent de l'impérialisme romain. Or, la thèse de la traîtrise de l'accusé, développée minutieusement par le témoin Saint Pierre, est énoncée par le Tigre, le président du tribunal, parmi les conclusions auxquelles est arrivée la commission chargée des textes bibliques: "En examinant votre cas, la commission chargée des textes évangéliques est arrivée aux conclusions suivantes : toutes vos paraboles étaient réactionnaires. Consécration de l'injustice et de l'arbitraire; du salaire inique. Un exemple: le serf, qui primé, gagna cent pour cent... Leçons contre le divorce et en faveur de l'adultère. Plan quinquennal de la flatterie et du mensonge. Vous étiez un spermatozoïde farouche de la bourgeoisie, et rien de plus. Elle avait des raisons suffisantes de vous déifier. (...) Vous n'êtes pas venu sur terre pour abroger la Loi, mais pour l'accomplir.» Le sermon sur la montagne "était une nette provocation. Il préparait l'impérialisme romain. Vous ne pouvez pas nier vos rapports secrets avec Pilate. Le provocateur Judas et le fameux centurion étaient les ponts. Ils étaient tous intéressés par le monopole de l'huile. » (pp. 211, 212) 


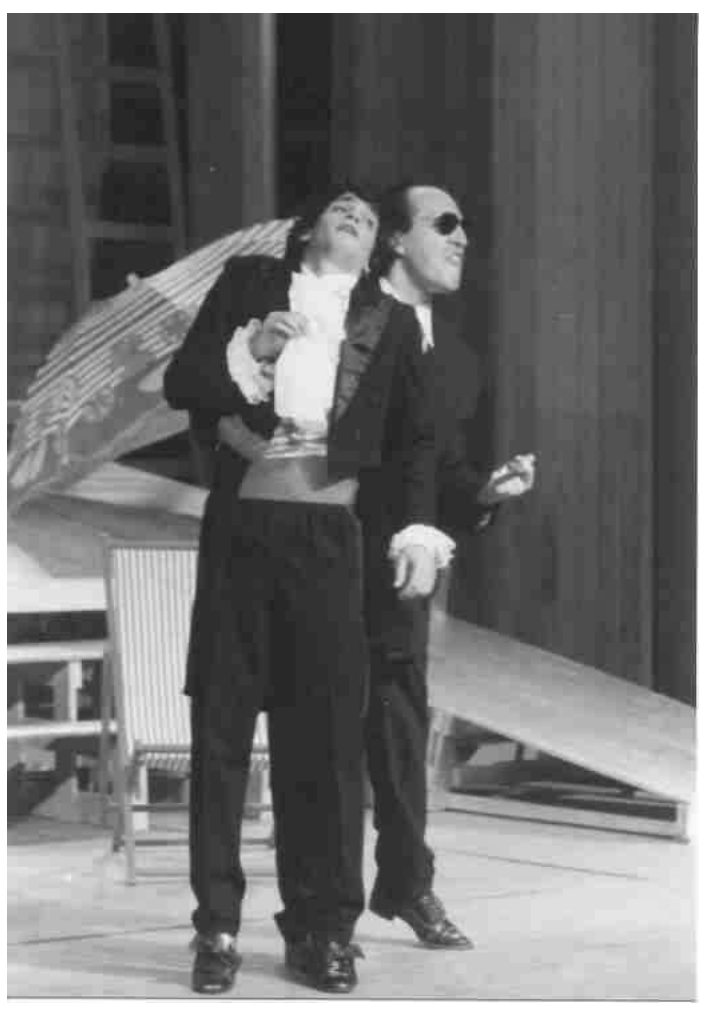

Cliché du Théâtre Universitaire de São Paulo parodique qui exploite la transgression iconoclaste et étale l'« esprit tendancieux ». La parodie, faut-il le rappeler, se définit en tant que discours divergent. La déformation du texte parodié (les Évangiles) s'explique par les orientations (courants d'opinions) personnelles qui sont installées dans le texte parodiant (le "procès d'agitation ") dont le but est d'examiner et d'évaluer des phénomènes mis en jugement, dans une perspective révolutionnaire, à savoir, à la lumière de la lutte des classes. Par le biais de l'accusé blasphémé, dégradé, privé de ses attributs sacrés dans le discours satirique l'orateur cherche à condamner les dogmes du christianisme, incompatibles avec l'idéologie marxiste. Ce "procès d'agitation" trouve dans le discours satirique un moyen efficace de combattre farouchement l'accusé, représentant le contexte adverse, dans la mesure où le but même de la satire est de dévoiler, railler et dénoncer ce qui constitue un achoppement pour le satiriste.

La « révision du procès du Christ », ou plus exactement, le jugement de l'accusé aboutit, par conséquent, à sa condamnation par le tribunal révolutionnaire, ainsi qu'à celle du baron Barabbas de Rothschild. Dernier personnage intertextuel à faire son apparition au tribunal, le personnage parodique Barabbas représente, comme il le dit lui-même, «les aspirations sionistes » de son peuple. «Philanthrope yankee», selon l'expression du personnage Véronique, Barabbas constitue, par ailleurs, un personnage type du théâtre d'agit-prop en tant que représentant des banques américaines. Aussi le baron Barabbas de Rothschild est-il caricaturé à souhait. Selon le texte didascalique, il est habillé «de façon très élégante; en frac. C'est le parfait capitaliste international. " «Es la banca internacional », précise, à son tour, Mme Jésus. À l'instar des «agitsud», la sentence prononcée par le président du tribunal exprime, en fait, l'«appréciation correcte» des jugements présentés par le tribunal rouge, selon un point de vue de 
classes : « les guides de la réaction » (la religion, l'Église), de même que les usuriers (les banquiers) doivent être condamnés.

Inhérent à la satire et à la parodie, le comique est à relever dans les réactions des deux accusés et dans les suggestions proposées par l'accusateur révolutionnaire, le Soldat Rouge.

LE CHRIST. - De nouveau, le Calvaire ! ;

BARABBAS. - De nouveau, les grilles ! (En s'adressant à Madeleine.) Allons, Mag ! ;

LE SOLDAT ROUGE - Sur le Golgotha sont restées les croix des deux larrons. Elles vous

iront à merveille. (p. 216)

Il est important de rappeler que le texte didascalique introducteur du tableau en question signale la présence de deux croix seulement sur le paysage classique du Golgotha s'ouvrant sur la salle du tribunal révolutionnaire. L'explication fournie par le président du tribunal s'en prend une nouvelle fois à l'Église catholique consentant à la vente des reliques :

LE TIGRE. - Le pape l'a vendue en petits morceaux. Nous n'en sommes pas responsables. (p. 217)

La destruction des symboles constitue l'un des ressorts de la satire. «Le satiriste qui se propose de montrer qu'un emblème sert à d'injustes fins ou qu'il est manipulé par des tyrans ou par des démagogues feint d'ignorer sa valeur symbolique et le présente avec autant de réalisme que possible comme un simple objet (...) Les religions, du fait qu'elles utilisent tout un réseau très complexe de symboles, sont particulièrement vulnérables à des attaques de ce genre. ${ }^{31}$ Symbole de la Passion, la croix du Christ est « désymbolisée » dans ce " procès d'agitation » par le tribunal révolutionnaire, et ce, à cause de l'Église elle-même qui, par son esprit marchand, a su la récupérer pour son profit personnel. Or, par le biais de l'accusé, c'est bel et bien l'Église qui en dernière instance est condamnée par le tribunal, ainsi que le montrent les derniers échanges verbaux entre l'accusé principal et ses accusateurs :

SAINT PIERRE.-Je demande que cette fois-ci les deux condamnés (le Christ et

Barabbas) soient crucifiés comme je le fus, avec la tête en bas.

LE CHRIST. - Pierre, qui l'eût cru ? Toi, pierre de mon Église !

LE TIGRE. - L'humanité a vécu vingt siècles en entendant ce calembour ! Ça suffit !

(p. 217)

39 À la protestation solitaire provenant du personnage clownesque Mme Jésus, suit la revendication populaire énoncée par des voix anonymes (protestation soutenue par les accusateurs et l'accusé Barabbas) pour que la Vérité puisse enfin se manifester. Image mise au service de la pensée, selon la définition de Walter Benjamin, l'allégorie est un procédé esthétique largement exploité par l'agit-prop, dans son souci permanent d'inviter le public spectateur à réfléchir et à agir. Représentée sur la scène d'agit-prop par le chœur ou par un acteur, l'allégorie image pensante, figure signifiante ${ }^{32}$ détecte partout les stratégies et les tactiques du profit, dans le but d'inciter à l'action, contrairement à l'allégorie baroque qui détectait la vanité des choses, la signature de la mort, et invitait à la contemplation. Dans le " procès d'agitation » qui nous concerne, la présence du personnage allégorique, la camarade Vérité, s'explique par des raisons bien spécifiques. Ainsi que nous l'avons précisé précédemment, c'est bien ce personnage qui, resté débout aux côtés du président du Tribunal, représente l'arbitre suprême, et, à la demande de la salle, est chargé d'exprimer la conclusion idéologique finale du procès. Par ailleurs, faut-il le rappeler, le militantisme de propagation de la foi, spécifique à la satire, implique la possession de la vérité de la part du satiriste, son désir 
de la répandre et de convertir le lecteur/spectateur. ${ }^{33}$ Cela dit, on peut relever quelques constatations concernant le discours enflammé du personnage, la camarade Vérité. Tout en prônant la défense de l'humanité défavorisée économiquement, le discours de ce personnage allégorique, qui clôt le tableau, s'adresse paradoxalement à une élite culturelle seule capable, dans le contexte brésilien des années trente de décoder les innombrables références historiques. Le rôle du chœur, c'est-à-dire des voix anonymes, est, d'ailleurs, de synthétiser l'idée centrale («c'est l'hypothèse progressiste!») développée par le personnage allégorique dans son discours. Quoi qu'il en soit, son dernier mot, mis en relief textuellement - KARL MARX - éclaire le sens de la vérité par une équation, on ne peut plus, élémentaire. Moment de gravité, contrastant avec le ton parodique, comique de la satire mise en œuvre dans ce "procès d'agitation", l'énonciation de la vérité, à savoir, l'exaltation du marxisme (l'ultime étape du progrès), vise donc à conclure le procès en question. En d'autres termes, le discours de la camarade Vérité confirme le verdict du tribunal révolutionnaire concernant le jugement du phénomène mis en accusation, c'est-à-dire, la réaction, représentée par les fascismes, la religion et l'Église catholique, le capitalisme, les valeurs et croyances bourgeoises, et incarné par l'accusé principal.

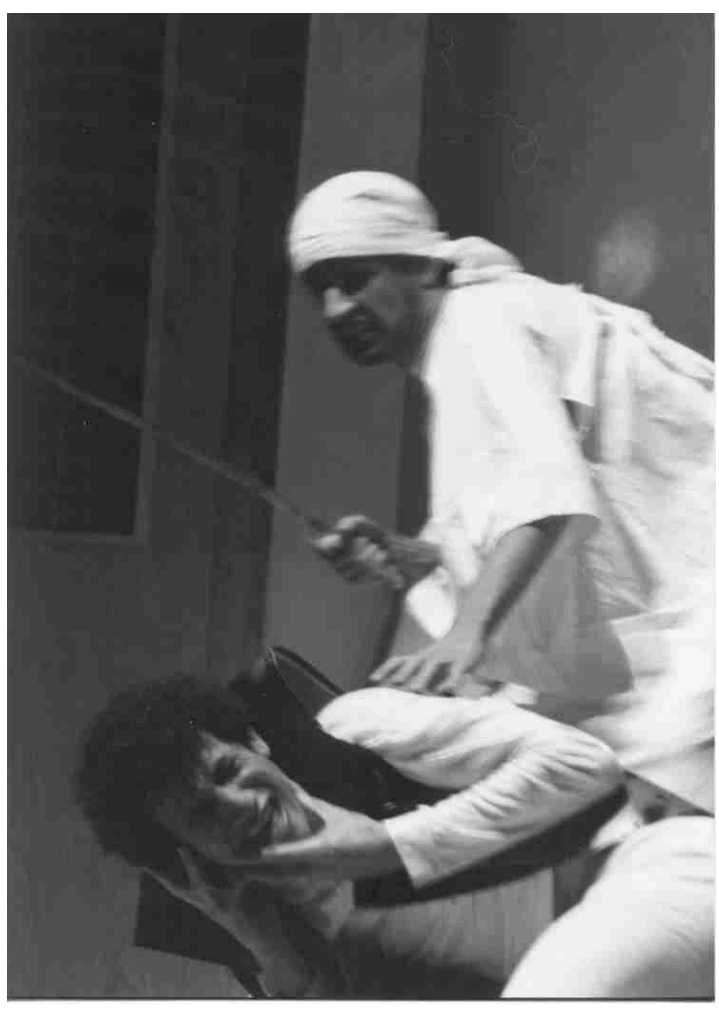

Cliché du Théâtre Universitaire de São Paulo

\section{Conclusion}

Contrairement au sérieux "agitsud " soviétique, le "procès d'agitation " " mis en scène » dans 0 homem e o cavalo, conçu sous la forme d'une satire parodique, constitue l'un des exemples les plus originaux de production agit-propiste. En introduisant la satire parodique, Oswald de Andrade a construit un tableau inédit où les innombrables trouvailles comiques le rendent beaucoup plus percutant que les «procès d'agitation » 
soviétiques. En effet, la présentation carnavalesque et clownesque du personnage Mme Jésus, provoquant l'hilarité et renforçant l'attaque satirique, affiche toute la subversion voulue par Oswald de Andrade dans ce procès d'agitation politique. En se servant $\mathrm{du}$ " montage des attractions » d'Eisenstein, conçu, rappelons-le, en vue d'une efficacité agitationnelle maximale, le dramaturge moderniste a su donc créer un "procès d'agitation" débordant d'inventions et de créations sur le plan textuel et scénique. Cela dit, le tableau en question renvoie au courant comique du théatre soviétique des années vingt pratiqué par le Front Gauche de l'Art (LEF), théâtre profondément irrespectueux où entrent cirque, music-hall, courant grotesque ou satirique ${ }^{34}$.

41 Ainsi que nous l'avons souligné dans les numéros précédents de Coulisses, le théâtre contestataire d'Oswald de Andrade, "théâtre de choc ", ne saurait être pleinement compris sans la référence à sa philosophie anthropophage. Travail d'absorption critique et de réélaboration originale d'autres textes/modèles, l'anthropophagie littéraire, faut-il le rappeler, s'accomplit par le biais de la déviation et du renversement des signes, transformant les multiples emprunts dans le but de puiser et de produire d'autres sens.

Schématique et austère, l'« agitsud » soviétique est transformé dans la pièce brésilienne en un "procès d'agitation " "spectaculaire "; autrement dit, un "spectacle " d'agitation comique carnavalisé. À l'aide des procédés esthétiques exploités par l'anthropophagie, telles la parodie, la vision grotesque et carnavalesque du monde, Oswald de Andrade innove une forme d'agitation théâtrale, dénudée de fantaisie, pour, tout d'abord, l'adapter au contexte brésilien des années trente, marqué par la réaction et la répression politique. Anarchique et provocateur, le "procès d'agitation" oswaldien vise non seulement à renforcer l'attaque satirique contre les accusés (incarnant les phénomènes jugés par le tribunal révolutionnaire), mais surtout à agresser l'adversaire - la bourgeoisie brésilienne.

L'un des traits distinctifs du discours d'agit-prop oswaldien concerne l'élargissement du champ de combat : les « vieilleries » esthétiques constituent aussi une cible à viser ${ }^{35}$. Il s'agit d'un combat politique et esthétique, à la fois, de la part du dramaturge avantgardiste. Composite, le discours militant dans Ohomem e ocavalo, est constitué de discours d'agitation et de propagande communiste, de discours d'agitation et de propagande nazi-fasciste, de discours d'agitation satirique iconoclaste, dans le «procès d'agitation", des discours chocs qui ne prennent tout leur sens que par leur propre effet de surprise et par des oppositions / rapprochements / confrontations. En se servant des procédés du montage dans la composition de O homem e ocavalo, Oswald de Andrade a su insérer, dans cette pièce, un discours d'agit-prop nouveau, dont l'impact sur le récepteur et sa force de théâtralité proviennent, en grande partie, de sa fragmentation (dispersion des multiples locuteurs-personnages en opposition idéologique ; éparpillement des innombrables contextes spatio-temporels) et de son hétérogénéité (actorielle, idéologique, interdiscursive, discursive, énonciative, événementielle, linguistique - portugais / espagnol / anglais / français / italien...; différents registres de langue...).Tout en empruntant/réélaborant des modèles européens (procédés du montage textuel / scénique; théâtre documentaire; théâtre d'agit-prop...), Oswald de Andrade, en exploitant le comique (parodique et satirique), a non seulement produit un discours d'agit-prop inédit, mais il a su forger une pièce politique sans précédent au Brésil. 


\section{NOTES}

1. Janvier 2001, Héliane kohler, «Philosophie anthropophage et pratique théâtrale au Brésil »; $\mathrm{n}^{\circ} 24$, mai 2001, «Le théâtre d'Oswald de Andrade expression d'un nouveau langage ».

2. Cf. les 4 tomes de Le théâtre d'agit-prop de 1917 à 1932, (Équipe "Théâtre Moderne » du GR 27, responsable : Denis B1ablet), Lausanne, La Cité L'Âge d'Homme, 1977 / 1978.

3. Cf. Héliane Kohler, «Quelques traits spécifiques de l'agit-prop discours politique et théâtral », in Mélanges offerts à Jean Peytard I, Annales littéraires de l'université de Besançon, 1993, pp. 239-248.

4. « Le Montage des Attractions », Au delà des étoiles, Paris, UGE (10/18), 1974, p. 117.

5. Cf. Le Théâtre Politique, Paris, L'Arche, 1972 (texte original 1929).

6. Claudine Amiard-Chevrel, "Méthodes et formes spécifiques », in Le théâtre d'agitprop, tome I, op.cit., pp. 49-61.

7. Voir Coulisses $n^{\circ} 24$, mai 2001, «Le théâtre d'Oswald de Andrade expression d'un nouveau langage ».

8. Journaliste américain, auteur de Dix jours qui ébranlèrent le monde, John Reed fut l'un des acteurs de la Révolution d'octobre.

9. Voir Coulisses $n^{\circ} 24$.

10. Claudine Amiard-Chevrel, op.cit., p. 53.

11. Ibid., p. 53.

12. Cf. «Un tribunal littéraire: La revanche du destin ». Article paru dans Front révolutionnaire (Kharkov), 5 février 1920, $\mathrm{n}^{\circ} 1$ sans mention d'auteur. Traduit par Jean-Pierre Morel, in Le théâtre d'agitprop de 1917 à 1932, Tome II, op.cit., p. 14.

13. Claudine Amiard-Chevrel, op.cit., p. 53.

14. Oswald de Andrade, o homem e o cavalo, Teatro, Rio de Janeiro, Civilizaçâo brasileira, 1978, p. 201.

15. Au sujet d'un procès d'agitation soviétique, «Un tribunal littéraire : La revanche du destin » (voir note $n^{\circ} 12$ ), l'article précise que «la pièce avait été précédée de quelques mots d'introduction sur l'essence du nouveau tribunal prolétarien et sur tout ce qui le différencie du tribunal du passé, qui reposait sur une autre base de classe. »

16. Claudine Amiard-Chevrel, "Le lit-montage ", in Collage et montage au théâtre et dans les autres arts, Lausanne, La Cité L'Âge d'Homme, 1978, p. 174.

17. Ibid., p. 174.

18. Linda Hutcheon, «Ironie, satire, parodie. Une approche pragmatique de l'ironie », Poétique $\mathrm{n}^{\circ} 46,1981$, p. 148.

19. Denise Jardon, Du comique dans le texte littéraire, Bruxelles, De Boeck-Duculot, 1988, p. 216.

20. Jacques Leenhardt, " $\mathrm{Au}$ cœur du débat Brecht-Lukacs. La satire», Cahiers d'histoire des littératures romanes, VIII, 1984. Cité par D. Jardon, ibid., p. 216.

21. Ibid., p. 216.

22. Anatomie de la critique, Paris, NRF, Gallimard, 1969, p. 272.

23. Ibid., p. 272.

24. Linda Hutcheon, op.cit., p. 146.

25. La parole pamphlétaire (Typologie des discours modernes), Paris, Payot, 1982, p. 34.

26. Le mot d'esprit et ses rapports avec l'inconscient, Paris, NRF, Gallimard, 1969, p. 152.

27. Claudine Amiard-Chevrel, « Le lit-montage », op.cit.; p. 171.

28. M. Angenot, La parole pamphlétaire (Typologie des discours modernes), op.cit., p. 34.

29. La satire, Paris, Hachette, 1969, p. 124.

30. M. Angenot, op.cit., p. 38. 
31. M. Hodgart, La satire, op.cit., p. 122.

32. Philippe Ivernel, « La problématique des formes dans l'agit-prop allemande ou la politisation radicale de l'esthétique ", in Le théâtre d'agit-prop de 1917 à 1932, tome III, op.cit., p. 68.

33. D. Jardon, Du comique dans le texte littéraire, op.cit.; p. 216.

34. Cf. Béatrice Picon-Vallin, "L'atelier de Foregger et le courant comique dans le théâtre soviétique », Du cirque au théâtre (Équipe « Théâtre Moderne » dru GR. 27 du C.N.R.S. responsable : Claudine Amiard-Chevrel), Lausanne, L'Âge d'Homme, 1983, p. 139.

35. Cf. Coulisses $n^{\circ} 24$, Héliane Kohler, «Le théâtre d'Oswald de Andrade expression d'un nouveau langage », op. cit., p. 69. 